\title{
Improved metabolic profiles in insulin-treated diabetic patients given an alpha-glucosidehydrolase inhibitor
}

\author{
R J WALTON, I T SHERIF, G A NOY, K G M M ALBERTI
}

British Medical fournal, 1979, 1, 220-221

\section{Summary and conclusions}

An alpha-glucosidehydrolase inhibitor (acarbose; BAY $\mathbf{g}$ 5421) taken with food was compared with dummy tablets in seven insulin-treated diabetic patients over eight-hour periods that included breakfast, lunch, and two snacks. Acarbose diminished the postprandial increases in blood glucose, lactate, and pyruvate concentrations and may therefore be of value in the management of insulindependent diabetes.

\section{Introduction}

Maintenance of blood glucose concentrations close to the normal range ${ }^{2}$ in insulin-dependent diabetes is seldom achieved with conventional treatment. One reason is that the absorption of carbohydrate from the intestinal tract is poorly matched by absorption of insulin from subcutaneous injection sites. Digestion of carbohydrate is brought about mainly by $\alpha$-glucosidehydrolases. These enzymes may be inhibited by the complex tetrasaccharide acarbose (BAY g 5421), which has particular affinity for sucrase and glucoamylase. ${ }^{34}$ This drug might therefore be of value in insulin-dependent diabetes by delaying the digestion and hence absorption of dietary carbohydrate. We report the short-term effects of adding acarbose to meals in such patients.

\section{Patients and methods}

Seven diabetic patients (four men and three women) aged 19-67 years, all well established (5-32 years) on insulin, were studied. All gave informed consent. None had hepatic, renal, or cardiovascular disease, and with one exception (who was obese) all were within $10 \%$ of ideal body weight. The investigation was designed as a doubleblind trial comparing acarbose tablets with identical-looking dummy tablets. Each patient was studied on two days at weekly intervals and thus served as his or her own control. Four patients received the active tablets first, and three the dummy tablets first. Patients took their customary diets and insulin on the preceding days and were studied after fasting overnight.

An indwelling intravenous cannula was inserted into a forearm vein at about 0800 and blood samples obtained without stasis at 0825 , 0830 , and at 30-minute intervals thereafter until 1630. Breakfast (bread, butter, egg, cereal, milk, and coffee) was taken between 0830 and 0900, a mid-morning snack (unsweetened biscuits and coffee) between 1030 and 1045, lunch (cheese, salad, bread, butter, jelly, ice cream, fruit, and coffee) between 1200 and 1230, and a mid-afternoon

Chemical Pathology and Human Metabolism, Faculty of Medicine, University of Southampton, Southampton SO9 4XY

R J WALTON, BSC, MRCP, lecturer

I T SHERIF, MB, CHB, senior house officer (present address: Department of Clinical Biochemistry, Royal Victoria Infirmary, Newcastle upon Tyne)

G A NOY, BSC, PHD, experimental officer (present address: Department of Clinical Biochemistry, Royal Victoria Infirmary, Newcastle upon Tyne)

K G M M ALBERTI, DPHI, FRCP, professor (present address: Department of Clinical Biochemistry, Royal Victoria Infirmary, Newcastle upon Tyne) snack (unsweetened biscuits and tea) between 1500 and 1515. Identical meals were taken on the two study days, the amount of carbohydrate in each being that to which each patient was accustomed. On the test day one acarbose tablet $(100 \mathrm{mg})$ was taken at the beginning of each meal and half a tablet $(50 \mathrm{mg})$ at the beginning of each snack. On the control day dummy tablets were taken.Blood samples were immediately deproteinised in perchloric acid $(15 \% \mathrm{v} / \mathrm{v})$ and later analysed for glucose, lactate, pyruvate, 3-hydroxybutyrate, glycerol, and alanine concentrations by automated enzymatic fluorometric techniques. ${ }^{5}$

Results are expressed as means $\pm \mathrm{SE}$ of mean. Differences between mean values on control and test days were assessed with Student's $t$ test for paired data.

\section{Results}

There was no significant difference between control and test days in mean basal values ( 0825 and 0830 ) of any biochemical variable.

After breakfast the mean blood glucose concentration (see figure) increased significantly on the control day (maximal increase $3 \cdot 8 \pm 1 \cdot 1$

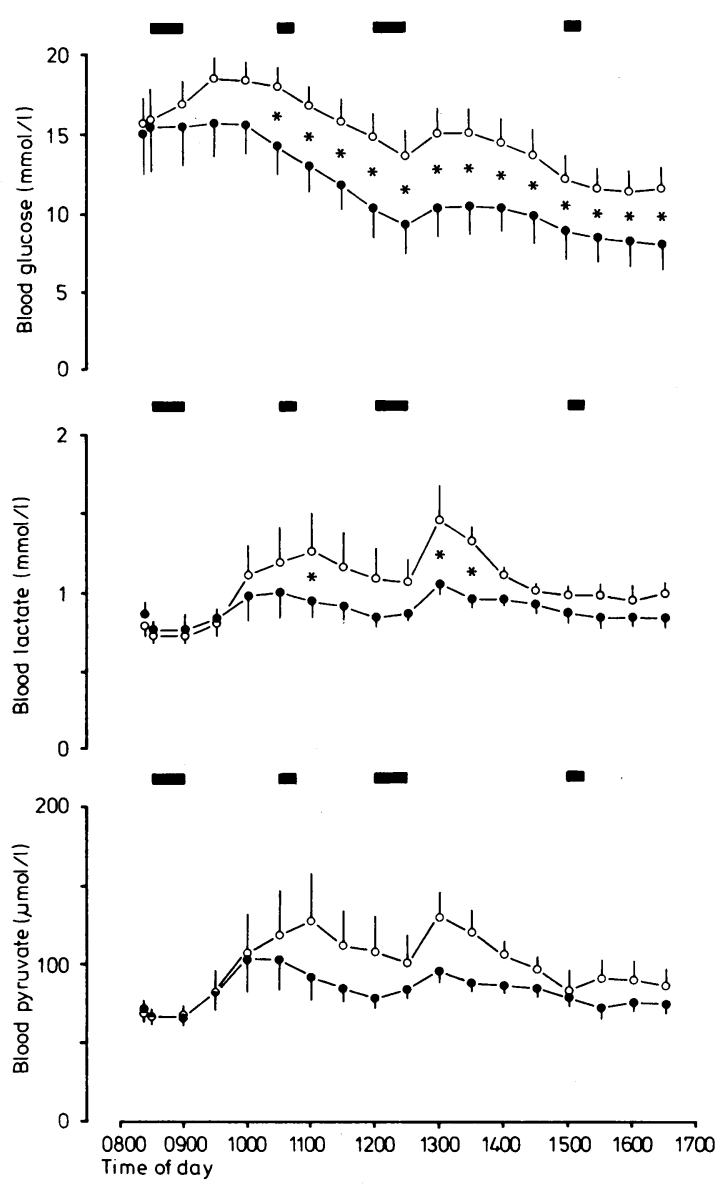

Effect of acarbose on mean ( \pm SE of mean) blood glucose, lactate, and pyruvate concentrations on control $(O)$ and tes (O) days. $=$ Meals and snacks. $*=$ Significant difference $(\mathrm{P}<0.05)$ between mean control and test day values.

Conversion: SI to traditional units-Glucose: $1 \mathrm{mmol} / 1 \approx$ $18 \mathrm{mg} / 100 \mathrm{ml}$. Lactate: $1 \mathrm{mmol} / 1 \approx 9 \mathrm{mg} / 100 \mathrm{ml}$. Pyruvate: $1 \mu \mathrm{mol} / 1 \approx 0.009 \mathrm{mg} / 100 \mathrm{ml}$. 
$\mathrm{mmol} / \mathrm{l} ; 68.5 \pm 19.8 \mathrm{mg} / 100 \mathrm{ml})(\mathbf{P}<0.001)$ but not on the test day (maximal increase $1 \cdot 3 \pm 1 \cdot 1 \mathrm{mmol} / 1 ; 23 \cdot 4 \pm 19 \cdot 8 \mathrm{mg} / 100 \mathrm{ml}$ ). Throughout the remainder of the study period blood glucose was significantly lower on the test day than on the control day, although after lunch it increased by similar increments on the two days. The average blood glucose value during the eight hours was significantly lower on the test day than on the control day $(11.2 \pm 1.6 \mathrm{mmol} / \mathrm{l}(202 \cdot 0 \pm 28.8 \mathrm{mg} / 100$ $\mathrm{ml})$ compared with $14.8 \pm 1.2 \mathrm{mmol} / 1(267.0 \pm 21.6 \mathrm{mg} / 100 \mathrm{ml})$ ) $(P<0.001)$. Qualitatively similar effects were seen in each patient studied, regardless of the order of treatment. Although none of the patients had symptoms of hypoglycaemia during the study, in two cases values of $2.8 \mathrm{mmol} / 1(50.5 \mathrm{mg} / 100 \mathrm{ml})$ were recorded towards the end of the test day.

Blood lactate concentrations tended to be lower throughout the test day than the control day, significant differences in peak values being recorded after breakfast and lunch (figure). The profile of mean blood pyruvate values was similar to that of lactate values (figure), although none of the differences between values on the control and test days reached significance $(P>0.05)$. No consistent changes were seen in the lactate to pyruvate ratio or in the mean blood concentrations of 3-hydroxybutyrate, glycerol, or alanine.

\section{Discussion}

Our results show that the $\alpha$-glucosidehydrolase inhibitor acarbose may greatly decrease the blood glucose concentration in insulin-treated diabetics, particularly after breakfast. This is presumably due to a reduction in the rate of absorption of glucose from the intestinal tract, although we cannot say whether this in turn is due solely to a prolongation of the time taken for carbohydrate to be absorbed or whether there is also a reduction in the total amount absorbed. In normal people the addition of $200 \mathrm{mg}$ acarbose to a $100 \mathrm{~g}$ oral load of sucrose causes $40^{\circ}{ }_{0}$ of the sucrose to pass unabsorbed through the small intestine. ${ }^{4} \mathrm{~A}$ comparable degree of carbohydrate malabsorption is to be expected in diabetics. The subsequent fermentation of nonabsorbed sugars by colonic bacteria leads to flatulence, which is a common and often unacceptable side effect of acarbose. The effects of the drug on blood lactate and pyruvate concentrations are less readily explained but may be due to a reduction in the rate of supply of glucose to the glycolytic pathway.

Other methods of slowing carbohydrate absorption in diabetics include adding the non-absorbable carbohydrate guar gum to food. ${ }^{6}$ ? Guar is thought to exert its effect mainly by delaying gastric empyting and thus has a different mode of action from that of acarbose. Acarbose has the important advantage that it may be taken as tablets with ordinary food. It remains to be seen whether a suitable treatment regimen can be devised for its use in the long-term management of insulin-dependent diabetes.

We thank Bayer UK Ltd for the supply of BAY g 5421 and for financial support; the British Diabetic Association for financial support; Dr I Hillebrand, Dr B Allen, and Mr D Lee for advice; and Miss P Smythe and Mrs B Lloyd for technical help.

\section{References}

${ }^{1}$ Job, D, et al, Diabetes, 1976, 25, 463.

2 Pirart, J, Diabète et Métabolisme, 1977, 3, 97.

${ }^{3}$ Schmidt, D D, et al, Naturwissenschaften, 1977, 64, 535.

${ }^{4}$ Caspary, W F, Lancet, 1978, 1, 1231.

${ }^{5}$ Lloyd, B, et al, Clinical Chemistry. In press.

6 Jenkins, D J A, et al, Lancet, 1976, 2, 172.

7 Jenkins, D J A, et al, British Medical fournal, 1978, 1, 1392.

(Accepted 8 November 1978)

\title{
Diet, sunlight, and 25-hydroxy vitamin $D$ in healthy children and adults
}

\author{
E M E POSKITT, T J COLE, D E M LAWSON
}

British Medical fournal, 1979, 1, 221-223

\section{Summary and conclusions}

In 110 white West Midlands children serum 25-hydroxy vitamin D (25-OHD) concentrations showed a pronounced seasonal variation, the values being highest in August and lowest in February. The concentrations correlated significantly both with recorded sunlight and with seasonal ultraviolet energy of the sunlight. Children who had had a seaside holiday the previous summer had a higher mean 25-OHD concentration than those who had not had a summer holiday away from home. Correlation between vitamin $D$ intake and serum 25-OHD concentration was not significant.

\footnotetext{
Institute of Child Health, Alder Hey Children's Hospital, Liverpool L12 2AP

E M E POSKITT, MB, MRCP, senior lecturer in child health

MRC Dunn Nutrition Unit, Dunn Nutrition Laboratory, Cambridge CB4 1XJ

T J COLE, MA, BPHIL, member of scientific staff

D E M LAWSON, BSC, PHD, member of scientific staff
}

In February 1977 serum 25-hydroxycholecalciferol and 25-hydroxyergocalciferol concentrations were measured in 11 healthy adults in Cambridge. The mean serum concentration of 25-hydroxycholecalciferol was higher than that of 25-hydroxyergocalciferol. After $5 \mu \mathrm{g}$ ergocalciferol daily for 28 days the mean serum concentration of 25-hydroxyergocalciferol was significantly increased but still lower than the 25 -hydroxycholecalciferol value.

The studies provide further evidence that even in winter serum 25-OHD values in normal people are determined more by previous exposure to summer sunlight than by dietary intake of vitamin $D$.

\section{Introduction}

Vitamin D is derived by man both from food and from ultraviolet irradiation of 7-dehydrocholesterol in the skin. In the early 1920 s Chick in Vienna showed that either oral cod-liver oil or exposure to summer sunlight would prevent and cure rickets in infants. ${ }^{1}$ At that time the relative importance of the two sources of calciferol in maintaining normal vitamin $\mathrm{D}$ nutrition was not clear. Now, however, we can measure the main circulating metabolite of vitamin D (25-hydroxy vitamin D; 25-OHD) and separate it into 25 -hydroxyergocalciferol derived solely from the diet and 25-hydroxycholecalciferol either derived from the diet 